Correction

\title{
Correction: Tendler, M., et al. Current Status of the Sm14/GLA-SE Schistosomiasis Vaccine: Overcoming Barriers and Paradigms towards the First Anti-Parasitic Human(itarian) Vaccine. Trop. Med. Infect. Dis. 2018, 3,121
}

\author{
Miriam Tendler*, Marília S. Almeida, Monica M. Vilar, Patrícia M. Pinto and \\ Gabriel Limaverde-Sousa
}

FIOCRUZ_-Instituto Oswaldo Cruz, Laboratório de Esquistossomose Experimental, Av. Brasil, 4365, Manguinhos, Rio de Janeiro 21045-900, Brazil; sirianni@ioc.fiocruz.br (M.S.A.); mvilar@ioc.fiocruz.br (M.M.V.); pmpinto@ioc.fiocruz.br (P.M.P.); gabriel.sousa@ioc.fiocruz.br (G.L.-S.)

* Correspondence: tendlermiriam@gmail.com; Tel.: +55-21-2562-1320

The authors wish to make the following correction to this paper [1]:

Where it reads:

"In order to have a consistent, stable and defined final product for clinical human use, the Sm14 antigen was formulated with the synthetic adjuvant glucopyranosyl lipid A (GLA-SE), clinically-approved molecule already used in a number of commercially-available human vaccines."

It should read:

"In order to have a consistent, stable and defined final product for clinical human use, the Sm14 antigen was formulated with the synthetic adjuvant glucopyranosyl lipid A (GLA-SE), an adjuvant successfully tested in clinical trials with different human vaccine candidates."

The authors would like to apologize for any inconvenience caused to the readers by this change.

\section{Reference}

1. Tendler, M.; Almeida, M.S.; Vilar, M.M.; Pinto, P.M.; Limaverde-Sousa, G. Current Status of the Sm14/GLA-SE Schistosomiasis Vaccine: Overcoming Barriers and Paradigms towards the First Anti-Parasitic Human(itarian) Vaccine. Trop. Med. Infect. Dis. 2018, 3, 121. [CrossRef] [PubMed]

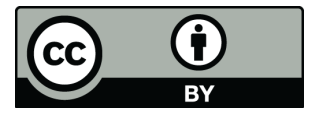

(C) 2019 by the authors. Licensee MDPI, Basel, Switzerland. This article is an open access article distributed under the terms and conditions of the Creative Commons Attribution (CC BY) license (http:/ / creativecommons.org/licenses/by/4.0/). 